\title{
REFORMING THE TAXATION OF MULTIJURISDICTIONAL ENTERPRISES IN EUROPE, "COOPETITION" IN A BOTTOM-UP FEDERATION
}

\author{
MARCEL GÉRARD \\ CESIFO WORKING PAPER NO. 1860 \\ CATEgory 1: Public FinANCE \\ NOVEMBER 2006
}

An electronic version of the paper may be downloaded

- from the SSRN website:

- from the RePEc website:

wWw.SSRN.com

- from the CESifo website:

Www.RePEc.org

www.CESifo-group.de 


\title{
REFORMING THE TAXATION OF MULTIJURISDICTIONAL ENTERPRISES IN EUROPE, “COOPETITION” IN A BOTTOM-UP FEDERATION
}

\begin{abstract}
This paper investigates replacing separate taxation by consolidation and formulary apportionment in a Bottom-up Federation, when a multijurisdictional firm is mobile in various respects. The reform is decided cooperatively by all the jurisdictions or by some of them, while tax rates remain within the competence of each jurisdiction. The paper sets forth the conditions for the reform to be social welfare enhancing, while not increasing tax competition. Among them, the formula should emphasize criteria that the Multijurisdictional Enterprise cannot easily manipulate and the consolidating area should protect its capacity to levy taxes by adopting a crediting system, possibly extended to accrued capital gains, vis-àvis the rest of the world. Policy conclusions are suggested accordingly.
\end{abstract}

JEL Code: H32, H73, H87.

Keywords: taxation of multinational enterprises, consolidation and formulary apportionment, fiscal federalism.

\author{
Marcel Gérard \\ FUCaM, Catholic University of Mons \\ Department of Economics and Sociology \\ Chaussée de Binche 151 \\ 7000 Mons \\ Belgium \\ gerard@fucam.ac.be
}

October 30, 2006

This paper was prepared during a sabbatical leave from Fucam, at Queen's University and CESifo. I am indebted to the Belgian FNRS for financial support, to Robin Boadway and CESifo for their hospitality, and to Thiess Buettner, Sam Bucovetsky, Andreas Haufler, Nadine Riedl, Marko Runkel, Peter Sorensen, Frans van Istendael and other participants at various seminars in Toronto, Montreal, Ottawa, Brussels, Munich and Lexington for their comments and critiques. 


\section{Introduction}

This paper is motivated by, and expects to contribute to, the present debate on the taxation of multijurisdictional enterprises (MJE's) in the European Union. On the one hand, both the EU Commission (European Commission, 2001a) and the enterprises (UNICE, 2000) complain about the tax obstacles to the operation of a true single market, including the need for MJE's to learn as many tax systems as there are Member States - although MJEs may in fact benefit from the strategic opportunities provided by this variety of tax systems. On the other hand Member States are attached to their exclusive right to decide on tax rates (a sign of their sovereignty - indeed for those in the Eurozone the sole remaining economic sign of that sovereignty) and to one of the basic principles of the EU, the subsidiarity principle, which implies that as much power as possible should be kept at the lowest possible level of government (in this case at the level of Member States rather than the EU Commission). One way to resolve this tension might be to change the taxation of Multijurisdictional Enterprises from separate accounting (SA) to consolidation with formulary apportionment (C\&FA) a reform that the EU Commission proposed in 2001 (European Commission, 2001a; 2003). Notice that, throughout this paper we use the term 'Multijurisdictional' enterprise deliberately: the European Union is sufficiently integrated for the word 'Multinational' no longer to be adequate, but not sufficiently integrated to justify the use of the word 'Multistate'; the more neutral 'Multijurisdictional' seems appropriate to designate an enterprise operating in various Member States of this bottom-up federation.

By a bottom-up federation, we mean a federation in progress, where the centre has the power delegated by the members. To complete the explanation of the title, "coopetition" refers to a key characteristics of that federation: decisions as to the design of the tax system - whether or nor adopting C\&FA, and which formula to decide - have to be taken at unanimity of member states or by a coalition of them - thus cooperatively - while the tax rates remain within the competence of each jurisdiction and may be decided noncooperatively in a tax competition framework.

The reader not familiar with interjurisdictional taxation may like to know that European MJEs are now taxed according to a SA system: each legal entity, or sometimes each national entity, is taxed on its own profit and tax relations between affiliates in different jurisdictions are ruled by tax treaties designed along the lines of the OECD model (OECD, 1996), possibly supple- 
mented by EU Directives such as the July 1990 Directive on the circulation of dividends between parent companies. This system is typical of relations within a network of sovereign states, each being free not only to decide on its own tax rates but also to define, for example, how to compute the tax base. Belgium, for instance, has just decided to move to an ACE system of computing the tax base, allowing companies to offset some fraction of their equity against their corporate tax base (Gérard, 2006a,b). By contrast, more advanced federations, such as the US and, for some taxes, Germany, have adopted C\&FA: a single tax base is first computed for all the affiliates of the same parent company, according to a given set of tax rules. This consolidated tax base is further distributed among the jurisdictions where the affiliates operate, according to predetermined rules, in order to be taxed by each of them at its own tax rate. Canada has adopted FA but without consolidation across the legal entities of a group of related companies. This combination of a single set of tax rules to compute a consolidated tax base and tax rates decided by each jurisdiction separately appears to enable C\&FA to resolve the tension discussed above. For lessons for Europe from the US and Canadian experiences see Hellerstein and McLure (2004), Weiner (2005) and Martens-Weiner (2006); on the US application of the system, see also Goolsbee and Maydew (2000). ${ }^{1}$

To explore this debate, this paper employs the following modeling strategy: a single MJE and three jurisdictions playing a six-Step game in three different settings.

The single MJE will be, depending on the setting of the game, one-, twoor $n$ - degree mobile. By a $n$ - degree mobile MJE we mean a MJE with $(n+$ 1) characteristics (such as the geographic distribution of its investments, the

\footnotetext{
${ }^{1}$ The C\&FA system, which has been extensively examined and discussed by experts and the parties concerned, certainly has the great advantage (providing it is sufficiently widespread) of putting an end to a certain number of tax strategies which MJEs find it in their interest to practice. As shown by the seminal work of Gordon and Wilson (1986) and the studies motivated by the planned reform in Europe - see Sorensen (2004) and the other references at the end of this article — such a reform could, however, under some conditions, increase tax competition between jurisdictions.. Therefore the selection of the formula is a key political decision. The EU Commission has proposed, as an intermediate step towards consolidation and formulary apportionment, that international compensation of losses between companies operating in the EU and belonging to the same MJE should be allowed. For an analysis of this issue see Gérard and Weiner (2003; 2005) and Weiner and Gérard (2004). Notice also that this paper continues our research work on that topic, see also Gérard (2003, 2005a,b).
} 
origins of its sales to final customers, the fraction of the financial investment and profits channeled through a passive jurisdiction), $n$ of which are under its control while one is not. ${ }^{2}$

Three jurisdictions play in the game, two of them being active, and one passive. An active jurisdiction hosts an active affiliate of the MJE, i.e. an affiliate which actually produces and/or sells, and is a market for the MJE. A passive jurisdiction is solely a financial center and will not be present in all the settings of the game; such a jurisdiction has a lower tax rate but is deemed to be located within the EU so that it will not be considered as a tax haven by the other two. The jurisdictions may differ between each other in terms of tax rates, size etc.

Three settings will be considered. In the first one, the MJE only decides on the distribution of its production (and thus of its investment) between the two active jurisdictions - it is one-degree mobile - the distribution of final demand being given, and being satisfied by the local affiliate. However intra-MJE trade is possible using an at arm's length transfer price ${ }^{3}$, so that the revenue of an affiliate depends on its sales both to the final customers and to the affiliate in the other jurisdiction. In a second setting, the need to sell to the final customers through the local affiliate is removed, so that it is now possible for a given affiliate of the MJE to sell directly to the customers in the territory of the other affiliate. The MJE then decides on the distribution of its production and the origin of its sales - in other words it is two-degree mobile; alternatively it could decide on a (risky) transfer price departing from the at arm's length one, or on a management fee or a royalty. In the

\footnotetext{
${ }^{2}$ More formally, a $n$-degree mobile MJE is a point in a $(n+1)$-dimension space

$$
M J E_{0}=\left(\mathbf{x}_{0}, q\right) \in \prod_{h=1}^{n+1}[0,1]_{h}
$$
}

where $\mathbf{x}$ is a vector of length $n$ of variables under the control of the firm, $\mathbf{x}_{0}$ being the initial value of that vector, and $q$ is the variable that the firm does not control. The firm may decide to move to another point in that space

$$
M J E=(\mathbf{x}, q) \in \prod_{h=1}^{n+1}[0,1]_{h}
$$

in order to maximize its own value $V$.

${ }^{3}$ In application of Oecd Model Tax Convention art. 9.1 - see OECD, 1996 - transactions between interdependent firms have to be realized using the same price as for transactions with unrelated parties. 
final setting, the MJE may transfer profits - up to an upper limit — to an affiliate in the passive jurisdiction, gaining an additional element of mobility. ${ }^{4}$

In all these settings the tax system is deemed to obey the exemption principle: under SA local profits are taxed locally and further repatriation to the parent company does not involve any extra tax liabilities. Moreover, interest payments are fully deductible against the tax base of the paying entity.

The six steps of the game are in line with the evolution of the European Union, the first three corresponding to the game played under SA, the last three to the game under C\&FA.

The first step, in some sense, corresponds to the pre-EU state of Europe and provides the players with an initial situation: in the two-degree mobile setting the distribution of the investment, and thus of the production, is determined by, say, the natural advantages that the jurisdictions have, and the distribution of demand by the respective size of those jurisdictions. In the second step, a single market comes into effect and interjurisdictional tax competition starts, generating a Nash equilibrium in tax rates, to which the MJE adapts in the third step.

In the fourth Step the jurisdictions may decide to move from SA to C\&FA and, if they move, they decide on the formula. The jurisdictions remain free to engage in further tax competition in the fifth step, the MJE adapting to that new situation in the sixth and final step. In some sense, the fourth step, and maybe the fifth step, are today's EU while the fifth and sixth are tomorrow's. However what will happen tomorrow might be anticipated today in such a way that steps 4 and 5 are quasi-simultaneous: the jurisdictions decide on the new system and possibly revise their tax rates accordingly during the same period - in the paper we consider those steps simultaneously.

In the EU, decisions on tax matters must be adopted either unanimously or by a number of Member States acting together in the framework of an Enhanced Cooperation Agreement (see Bordignon and Busco, 2006). Therefore we assume that the decision to move to C\&FA and the definition of the formula are either taken by all the jurisdictions cooperatively (in this we differ from Wellisch, 2004), or solely by the active ones, again acting cooperatively.

In other words, in this model, the decision as to the system - SA or $\mathrm{C} \& \mathrm{FA}$ - and the formula if C\&FA is taken cooperatively, while the decisions as to the tax rates are taken non-cooperatively.

\footnotetext{
${ }^{4}$ On that last setting see also Mintz and Smart (2004).
} 
Some policy lessons arise from this exercise. In particular, the reform might be supported provided that (1) the formula puts emphasis on criteria that the firm cannot easily manipulate; (2) real investment is actually mobile; (3) the consolidation is made compulsory within the consolidating area; and (4) the consolidating area protects its capacity to actually levy tax by adopting a crediting system, possibly extending to accrued capital gains, vis-à-vis the rest of the world. This last recommendation is valid even if the reform is adopted by the entire EU, as long as the EU is not disconnected from the rest of the world. That last remarks enlarges the scope of the paper: despite its motivation by a possible change in the EU, it is not without interest for other regions in the world, especially those where federation building processes are in progress, nor for the taxation of MJE's across the whole world.

This paper is organized as follows. After this introduction, Section 2 considers a one-degree mobile MJE and Section 3 a two- or more- degree mobile MJE, taking into account strategic opportunities offered by the SA tax system, and dealing successively with tax shifting and paper profits, profitable detour and inter-modal finance, and with the issue of the adoption of the reform by either the whole EU or a subset of Member States within an Enhanced Cooperation Agreement. Conclusions and avenues for further research are discussed in Section 4.

In addition to the contributions already mentioned, several interesting papers on related topics exist, including Eggert and Schjelderup (2003), Nielsen et al. (2003), Pethig and Wagener (2003), Eichner and Runkel (2006) and Riedl and Runkel (2006).

\section{A one-degree mobile MJE}

The one-degree mobile firm has two characteristics observed by the players in Step 1: on the one hand it has invested a fraction $\alpha_{0}$ of its total investment and produces that fraction of its total production, in jurisdiction $i$, and the complement $1-\alpha_{0}$ in jurisdiction $j, i$ and $j$ being the two active jurisdictions; on the other hand it needs to deliver a fraction $q$ of its production to the market in jurisdiction $i$ and $1-q$ to the market in $j$. The MJE can change the first characteristics by moving part of its real investment from one jurisdiction to the other, substituting $\alpha$ for $\alpha_{0}$. However such a move has a cost $c(\alpha)$. The second characteristics is not controlled by the MJE. 
In other words the MJE is

$$
M J E_{0}=\left(\alpha_{0}, q\right) \in[0,1] \times[0,1]
$$

and may decide to move to another point

$$
M J E=(\alpha, q) \in[0,1] \times[0,1]
$$

in that space in order to maximize its value, at Steps 3 and 6 of the game, (more precisely at Step 3 under SA and at Step 6 under C\&FA). As discussed in the introduction, the one-degree mobile MJE evolves in a two-jurisdiction setting where $q$ must be satisfied by the affiliate in $i$ and $1-q$ by its counterpart in $j$. The retail price paid by the final customers is denoted by $p ; p$ is a net price in the sense that it may be regarded as a retail price net of operational costs, including wage costs. Moreover intra-MJE trade is possible and is conducted at a wholesale price $p^{w} \leq p$; the wholesale price is also a net price which may differ from the retail price to the extent that it does not incorporate the cost of preparing the good for the final sale. At the extreme, both prices may be equal; otherwise the retail price is larger.

By "enough mobile" we mean that in response to a tax differential incentive $\tau_{j}<\tau_{i}$, the cost of moving real activity from jurisdiction $i$ to jurisdcition $j$, denoting by $c(\alpha)$ - see equation (3)below - is small enough to enable the MJE to move from $\alpha_{0}-q>0$ to $\alpha-q<0$.

Bearing this in mind we first investigate the game under SA, then that under C\&FA, resolving backwards in both cases.

\subsection{Separate Accounting}

Under separate accounting, each affiliate of the MJE is taxed separately on its own profit. We assume that the exemption principle is at work so that profit taxed at the level of the affiliate in one jurisdiction is not taxed again when distributed to the parent company - this implies that profit is repatriated as a dividend to the parent company located in $i$.

We resolve the game backwards. Let us thus examine Step 3 first and then Step 2.

\subsubsection{The MJE under SA}

In Step 3, the one-degree mobile firm maximizes its long run value with respect to the variable under its control, the distribution of its investment. 
Thus

$$
\max _{\alpha} V(\alpha)=\frac{p}{r}-\tau_{i} B_{i}-\tau_{j} B_{j}-c(\alpha)
$$

where

$\frac{p}{r}$ is the discounted flow of gross receipts, $r$ being a discounting rate

$\tau_{i} B_{i}$ and $\tau_{j} B_{j}$ are tax liabilities in jurisdictions $i$ and $j$ respectively, and $c(\alpha)$ is the cost of changing the distribution of real investment from its initial distribution.

Furthermore, the tax bases are defined as

$$
\begin{aligned}
B_{i} & =q \frac{p}{r}+(\alpha-q) \frac{p^{w}}{r} \\
B_{j} & =(1-q) \frac{p}{r}-(\alpha-q) \frac{p^{w}}{r}
\end{aligned}
$$

or rearranging,

$$
\begin{aligned}
B_{i} & =\left[q\left(1-\frac{p^{w}}{p}\right)+\alpha \frac{p^{w}}{p}\right] \frac{p}{r} \\
B_{j} & =\left[(1-q)\left(1-\frac{p^{w}}{p}\right)-\alpha \frac{p^{w}}{p}\right] \frac{p}{r}
\end{aligned}
$$

which sets forth the relative emphasis of sales, $q$, and investment and thus production, $\alpha^{5}$. The cost of changing real investment from its initial distribution is

$$
c(\alpha)=\frac{\gamma}{2}\left(\alpha-\alpha_{0}\right)^{2}
$$

${ }^{5}$ Rewritten in terms of elasticity, we have that

$$
E_{B_{i} q}=1-E_{B_{i} \alpha}
$$

with

$$
E_{B_{i} \alpha}=\frac{\frac{p^{w}}{p} \alpha}{\left(1-\frac{p^{w}}{p}\right) q+\frac{p^{w}}{p} \alpha}
$$

and the relative elasticity of the tax base to its "factors" is

$$
\frac{E_{B_{i} q}}{E_{B_{i} \alpha}}=\frac{\left(p-p^{w}\right) q}{p^{w} \alpha}
$$


It turns out from the first order condition of the maximization of equation (1) with respect to $\alpha$ that the equilibrium value of that variable is

$$
\alpha^{q}=\alpha_{0}+\frac{\tau_{j}-\tau_{i}}{\gamma} \frac{p^{w}}{r}
$$

The sensitivity of firm to tax changes is then

$$
\frac{d \alpha^{q}}{d \tau_{i}}=\frac{-p^{w}}{\gamma r}, \frac{d \alpha^{q}}{d \tau_{j}}=\frac{p^{w}}{\gamma r}
$$

The second order condition of the maximization of $V$ with respect to $\alpha$ holds, since

$$
\frac{d^{2} V}{d \alpha^{2}}=-\gamma<0
$$

Replacing $\alpha^{q}$ by its equilibrium value in (1), the value of the firm in terms of the tax parameters, or "indirect" value, is

$$
\begin{aligned}
V^{q}= & \frac{p}{r}-\tau_{i}\left[q \frac{p}{r}+\left(\alpha_{0}-q+\frac{\tau_{j}-\tau_{i}}{\gamma} \frac{p^{w}}{r}\right) \frac{p^{w}}{r}\right] \\
& -\tau_{j}\left[(1-q) \frac{p}{r}-\left(\alpha_{0}-q+\frac{\tau_{j}-\tau_{i}}{\gamma} \frac{p^{w}}{r}\right) \frac{p^{w}}{r}\right] \\
& -\frac{\gamma}{2}\left(\frac{\tau_{j}-\tau_{i}}{\gamma} \frac{p^{w}}{r}\right)^{2}
\end{aligned}
$$

\subsubsection{The jurisdictions under SA}

Suppose that each government maximizes a Social Welfare Function - Step 2 of the game - defined on the welfare of its own residents deemed to depend on the share $s_{i}$ of the value of the MJE, $V$, owned by those residents, on the effect of the investment on local employment, say $w_{i} \alpha / r$ in jurisdiction $i$ where $w_{i}$ is the shadow price of hiring a worker in $i$ (see Boadway and Bruce, 1984), and on the amount of public goods available to the residents, $u_{i} \tau_{i} B_{i}$ in jurisdiction $i, u_{i}$ being the shadow price of public goods in jurisdiction $i$. For the sake of simplicity, we assume that $s_{i}=s_{j}=s \leq 1 / 2 ; w_{i}=w_{j}=w$ and $u_{i}=u_{j}=u>1$. Thus, for jurisdiction $i$,

$$
W_{i}=s V+\frac{w \alpha}{r}+u_{i} \tau_{i} B_{i}
$$


has to be maximized with respect to tax rate $\tau_{i}$.

The first order condition of that maximization implies a reaction function

$$
\tau_{i}^{q}=\frac{u-s}{2 u-s}\left[\frac{q p+\left(\alpha_{0}-q\right) p^{w}}{\left(p^{w}\right)^{2}} \gamma r-\frac{1}{u-s} \frac{w}{p^{w}}+\tau_{j}^{q}\right]
$$

whose slope is positive and smaller than one. In order to have positive tax rates at Nash equilibrium, we assume that the intercept is positive. It turns out that the tax rates at Nash equilibrium is such that,

$$
\begin{aligned}
\tau_{i}^{q} & =\frac{\theta}{\rho} A_{i}+\frac{\theta^{2}}{\rho} A_{j} \\
\tau_{j}^{q} & =\frac{\theta}{\rho} A_{j}+\frac{\theta^{2}}{\rho} A_{i}
\end{aligned}
$$

with

$$
\begin{aligned}
\theta & =\frac{u-s}{2 u-s}, \rho=1-\theta^{2} \\
A_{i}^{q} & =\frac{q p+\left(\alpha_{0}-q\right) p^{w}}{\left(p^{w}\right)^{2}} \gamma r-\frac{1}{u-s} \frac{w}{p^{w}} \\
A_{j}^{q} & =\frac{(1-q) p-\left(\alpha_{0}-q\right) p^{w}}{\left(p^{w}\right)^{2}} \gamma r-\frac{1}{u-s} \frac{w}{p^{w}}
\end{aligned}
$$

Notice that it easy to calibrate those expressions in order to ensure that $\tau_{h}^{q}<1, h=i, j$. Interestingly,

$$
\begin{aligned}
\tau_{i}^{q}-\tau_{j}^{q} & =\frac{\theta}{1+\theta}\left(A_{i}^{q}-A_{j}^{q}\right) \\
& \propto(2 q-1) p+2\left(\alpha_{0}-q\right) p^{w}
\end{aligned}
$$

so that a sufficient condition for the tax rate in jurisdiction $j$ to be smaller than its counterpart in jurisdiction $i$ is $\alpha_{0}>q>1 / 2$; not surprisingly (and in line with NEG) the larger jurisdiction in terms of domestic investment and demand is the less aggressive in terms of tax rates.

Finally we can see that the second order condition holds since

$$
\frac{d^{2} W_{i}}{d \tau_{i}^{2}}=-\frac{2 u-s}{\gamma}\left(\frac{p^{w}}{r}\right)^{2}
$$


Some special cases of equation (8) deserve interest. First if the governments are Leviathan, then $s=w=0$ in the Social Welfare Function, and

$$
\tau_{i}^{q}=\frac{1}{2}\left[\frac{q p+\left(\alpha_{0}-q\right) p^{w}}{\left(p^{w}\right)^{2}} \gamma r+\tau_{j}^{q}\right]
$$

so that the intercept of the reaction function is larger than in the general case, and the equilibrium tax rate as well. Second, if the government is not interested in the welfare of shareholders or if no shareholder is resident in any of the jurisdictions concerned, then $s=0$ and

$$
\tau_{i}^{q}=\frac{1}{2}\left[\frac{q p+\left(\alpha_{0}-q\right) p^{w}}{\left(p^{w}\right)^{2}} \gamma r-\frac{1}{u} \frac{w}{p^{w}}+\tau_{j}^{q}\right]
$$

and the intercept and equilibrium tax rate are in between the general and Leviathan case. We see that, more than a Leviathan government, a government committed to the welfare of the workers, and a fortiori of the shareholders, will have an incentive to decrease the tax rate, pushing down its values at Nash equilibrium.

Finally notice that if retail and wholesale net prices coincide, $p^{w}=p$ and the reaction function becomes

$$
\tau_{i}^{q}=\frac{u-s}{2 u-s}\left[\frac{\alpha_{0}}{p} \gamma r-\frac{1}{u-s} \frac{w}{p}+\tau_{j}^{q}\right]
$$

\subsection{Consolidation and Formulary Apportionment}

Moving one to Consolidation and Formulary Apportionment, C\&FA, a consolidated tax base $B$ is first calculated, using equation (2) and canceling out intra-MJE flows. This is then distributed, or apportioned, between the two jurisdictions using a formula which is determined cooperatively by the two jurisdictions at Step 4 of the game.

We suppose here that the formula is a linear combination of real investment (or here equivalently production or labor cost) and gross receipts from final sales, with weights $\lambda$ and $1-\lambda$ respectively. Since wage costs are strictly proportional to investment in this model, the wage costs criterion can be disregarded. What is important for the purposes of this paper is that the distribution of one criterion - here real investment - is under the firm's control, and the distribution of the other is not. It turns out that that there 
is now a consolidated tax base, as well as two local tax bases given by

$$
\begin{aligned}
B & =\frac{p}{r} \\
B_{i}^{F A} & =[\lambda \alpha+(1-\lambda) q] B \\
B_{j}^{F A} & =[\lambda(1-\alpha)+(1-\lambda)(1-q)] B
\end{aligned}
$$

or rearranging,

$$
\begin{aligned}
B_{i} & =[q(1-\lambda)+\alpha \lambda] \frac{p}{r} \\
B_{j} & =[(1-q)(1-\lambda)-\alpha \lambda] \frac{p}{r}
\end{aligned}
$$

which sets forth the relative emphasis of sales, $q$, and investment and thus production, $\alpha^{6}$.

At Step 5 the jurisdictions may begin a new round of tax competition and at Step 6 the MJE revises its distribution of investment. Again we will look at the game backward, from Step 6 to Step 4. In some sense, steps 4 and 5 correspond to the present situation in the EU; in the analysis they are assumed to occur simultaneously.

\subsubsection{The MJE under C\&FA}

Substituting the last two lines of equation (9) for equation (2) into equation (1), we find that equations (4) and (5) are replaced by

$$
\alpha^{F A}=\alpha_{0}+\frac{\tau_{j}-\tau_{i}}{\gamma} \frac{\lambda p}{r}
$$

${ }^{6}$ Again, rewritten in terms of elasticity, we have that

$$
E_{B_{i} q}=1-E_{B_{i} \alpha}
$$

with

$$
E_{B_{i} \alpha}=\frac{\lambda \alpha}{(1-\lambda) q+\lambda \alpha}
$$

and the relative elasticity of the tax base to its "factors" is

$$
\frac{E_{B_{i} q}}{E_{B_{i} \alpha}}=\frac{(1-\lambda) q}{\lambda \alpha}
$$


and

$$
\frac{d \alpha^{F A}}{d \tau_{i}}=\frac{-\lambda p}{\gamma r}, \frac{d \alpha^{F A}}{d \tau_{j}}=\frac{\lambda p}{\gamma r}
$$

A comparison of $\lambda p$ and $p^{w}$ will then determine the sensitivity of real investment to tax differential: the sensitivity to tax rates (in absolute value) is higher under C\&FA if $\lambda p>p^{w}$.

Finally, the "indirect" value of the MJE becomes

$$
\begin{aligned}
V^{F A q}= & \frac{p}{r}-\tau_{i}\left[(1-\lambda) q+\lambda\left(\alpha_{0}+\frac{\tau_{j}-\tau_{i}}{\gamma} \frac{\lambda p}{r}\right)\right] \frac{p}{r} \\
& -\tau_{j}\left[(1-\lambda)(1-q)-\lambda\left(1-\alpha_{0}-\frac{\tau_{j}-\tau_{i}}{\gamma} \frac{\lambda p}{r}\right)\right] \frac{p}{r} \\
& -\frac{\gamma}{2}\left(\frac{\tau_{j}-\tau_{i}}{\gamma} \frac{\lambda p}{r}\right)^{2}
\end{aligned}
$$

\subsubsection{The jurisdictions under C\&FA, possible tax competition}

We are now at Step 5 of the game. As in Step 6, suppose that the formula is characterized by parameter $\lambda$. Then each government selects its corporate tax

rate in order to maximize the social welfare of its jurisdiction. For jurisdiction $i$, we have

$$
\tau_{i}^{F A}=\frac{u-s}{2 u-s}\left[\frac{\lambda \alpha_{0}+(1-\lambda) q}{\lambda^{2} p} \gamma r-\frac{1}{u-s} \frac{w}{\lambda p}+\tau_{j}^{F A}\right]
$$

Notice, as above, that

$$
\tau_{i}^{F A}-\tau_{j}^{F A}=\frac{\theta}{1+\theta}\left(A_{i}^{F A}-A_{j}^{F A}\right)
$$

or

$$
\tau_{i}^{F A}-\tau_{j}^{F A} \propto(1-\lambda)(2 q-1)+\lambda\left(2 \alpha_{0}-1\right)
$$

and the tax rate in jurisdiction $j$ will be smaller if $(1-\lambda)(2 q-1)+\lambda\left(2 \alpha_{0}-1\right)>$ 0 . Though a sufficient condition for that inequality to hold is $\alpha_{0}, q>1 / 2$ - a condition compatible with that $\alpha_{0}>q>1 / 2$ stated above -, it is interesting to note that for the extreme values of $\lambda$ we have $q>1 / 2(\lambda=0)$ and $\alpha_{0}>1 / 2(\lambda=1)$ : again the poorer jurisdiction is the more aggressive. Notice also that parameters are deemed to be such that tax rates are smaller than unity. 
However a key issue is: does the reform increase or decrease tax competition, or, more precisely, if the governments revise their tax rates solely in the best interests of their residents, will higher or lower rates of taxation result under C\&FA than under SA? To answer this question, let us compare the reaction function above with its counterpart under SA, equation (8). That comparison immediately reveals that the slope is identical while the intercept can be either larger or smaller. More precisely, the intercept is larger under $\mathrm{C} \& \mathrm{FA}$ if

$$
\left\{\lambda p^{w}\left[\alpha_{0} \gamma r-\frac{w}{u-s}\right]+\left[p^{w}+\lambda\left(p-p^{w}\right)\right] q \gamma r\right\}\left(p^{w}-\lambda p\right)>0
$$

The first term of this expression - that in brackets in the right hand side - is positive since, as already mentioned, we assume that

$$
\left(\lambda \alpha_{0}+(1-\lambda) q\right) \gamma r(u-s)-w>0
$$

in order to guarantee that the intercept is positive so that the tax rates at Nash equilibrium are positive too. As a consequence, the inequality will hold if the last term is also positive - i.e. if $p^{w}>\lambda p$ - which is the condition for the investment being less sensitive to tax changes after the reform.

Therefore, if the reform makes the MJE less sensitive to tax changes it will push the intercept of the reaction function upward and thus tax competition will decrease, or tax rates will increase. Conversely, if $p^{w}<\lambda p$ - i.e. if the reform makes the MJE more sensitive to tax changes - tax competition will be boosted. Considering the extreme cases, if $\lambda=1$ and $p^{w}<p$, tax competition is sharply increased: indeed in this situation the distribution of the tax base depends entirely on the distribution of real investment, which is the variable controlled by the MJE. Thus the reform increases the importance of the variable controlled by the firm in the determination of its tax liabilities, and the MJE gains in terms of freedom with respect to the tax authorities. Unlike that, if $\lambda=0$, the tax competition does not increase.

This discussion can be summed up in the following condition for no further tax competition,

Proposition 1 (No-further-tax-competition) In a two-jurisdiction and onedegree mobile MJE setting a sufficient condition for $\tau_{h}^{F A} \geq \tau_{h}^{q}, h=i, j$, is $\lambda p<p^{w}$.

Finally it is possible that revising the tax rates upwards would not be politically feasible. 


\subsubsection{Adopting C\&FA at unanimity}

Given the above definition of the consolidated tax base and the apportionment formula, as well as of the social welfare functions, the two jurisdictions jointly maximize $W=W_{i}+W_{j}$ with respect to $\lambda$ in Step 4 . However the reform will only be adopted if $W^{F A}-W^{q} \geq 0$ - remember that unanimity rule prevails in tax matters in Europe. This participation constraint ensures that a side payment will be made, if necessary, by the jurisdiction which stands to gain from the reform to that which stands to loose. To keep the problem tractable, we assume that Steps 4 and 5 are performed simultaneously: the jurisdictions deciding jointly on the reform and simultaneously, but separately, on the tax rates.

The first order condition of the cooperative maximization can be written

$$
\frac{d W}{d \lambda}=\left(\tau_{i}^{F A}-\tau_{j}^{F A}\right)\left[(u-s)\left(q-\alpha_{0}\right)-2(u-s) \lambda \frac{\tau_{j}^{F A}-\tau_{i}^{F A} p}{\gamma} \frac{p}{r}\right] \frac{p}{r}=0
$$

and the second order one

$$
\frac{d^{2} W}{d \lambda^{2}}=-2(u-s)\left(\frac{\tau_{j}^{F A}-\tau_{i}^{F A}}{\gamma} \frac{p}{r}\right)^{2}<0
$$

From the first order condition the equilibrium value of the apportionment formula can be obtained,

$$
\lambda^{W}=\frac{u-2 s}{2(u-s)} \frac{q-\alpha_{0}}{\tau_{j}^{F A}-\tau_{i}^{F A}} \frac{\gamma r}{p}
$$

with $\tau_{i}^{F A}$ and $\tau_{j}^{F A}$ determined at Step 5 above. Then, substituting the right hand side of equation (14) for $\tau_{i}^{F^{A}}-\tau_{j}^{F^{A}}$ in equation (17), we obtain

$$
\lambda^{W}=2\left(\frac{u-s}{u}\right)^{2} \frac{1-2 q}{\alpha_{0}-q}
$$

which needs to be comprised between 0 and 1 . Thus, especially if $\alpha_{0}>$ $q>1 / 2$, the realistic case where the smaller jurisdiction is more aggressive in terms of tax rates, the numerator of equation (18) is negative and the equilibrium value of $\lambda$ is zero: the consolidated tax base is distributed among the two jurisdictions in line with the distribution of sales, the variable not 
controlled by the MJE. In other terms, the constrained equilibrium formula is characterized by

$$
\begin{aligned}
\lambda^{W W} & =0, \lambda^{W}<0 \\
\lambda^{W W} & =\lambda^{W}, 0<\lambda^{W}<1 \\
\lambda^{W W} & =1, \lambda^{W}>1
\end{aligned}
$$

It turns out that the cooperatively determined equilibrium formula $\lambda^{W W}$ is compatible with the no-further-tax-competition condition if

$$
\max \left(\lambda^{W}, 0\right)<\frac{p^{w}}{p}
$$

which certainly holds if $\alpha_{0}>q>1 / 2$ since then $\lambda^{W W}=0$. However it also hold for a relatively large range of positive values of $\lambda^{W W}{ }^{7}$

To sum up,

Proposition 2 The cooperatively determined equilibrium formula $\lambda^{W W}$ is compatible with the no-further-tax-competition condition if inequality (20) holds, which will be certainly the case if $\alpha_{0}>q>1 / 2$.

However the reform will only be adopted if $W^{F A}-W^{q} \geq 0$. Then the two jurisdictions, considered together, experiment an aggregate welfare gain and a side payment is possible from that which individually experiments a welfare gain (the higher taxing jurisdiction actually) to that which loses individual welfare.

Therefore we need to show that

$$
(u-2 s)\left[\tau_{i}^{F A} B_{i}^{F A}-\tau_{i}^{q} B_{i}^{q}+\tau_{j}^{F A} B_{j}^{F A}-\tau_{j}^{q} B_{j}^{q}\right]-2 s\left[c\left(\alpha^{F A}\right)-c\left(\alpha^{q}\right)\right] \geq 0
$$

For that purpose we proceed in two steps. First, we assume that the nofurther-tax-competition condition holds, that conditions are fulfilled for $\tau_{j}-$ $\tau_{i}<0$ and that, tentatively, it is not politically feasible to increase tax rates after the reform. In that framework we show that there is an aggregate welfare gain; this is lemma 3 . Then we relax that last restriction and show that the aggregate welfare increases when the tax rates do - lemma 4.

\footnotetext{
${ }^{7}$ Notice that $\lambda^{W}<\frac{p^{w}}{p}$ means that in $B_{i}$ the relative weight given to sales with respect to investment or production is increased - see the footnotes above.
} 
Lemma 3 If the no-further-tax-competition condition holds, $\tau_{j}-\tau_{i}<0$ and tax rates are not permitted to increase after the reform, a move to CESFA characterized by $\lambda^{W W}$ is aggregate welfare increasing provided that real investment is "enough mobile".

The condition $W^{F A}-W^{q} \geq 0$ implies that

$$
\left\{(u-2 s)\left(\tau_{i}-\tau_{j}\right)\left[\alpha_{0}-q+\frac{\tau_{j}-\tau_{i}}{\gamma} \frac{\lambda p+p^{w}}{r}\right]-\frac{s}{\gamma}\left(\tau_{j}-\tau_{i}\right)^{2} \frac{\lambda p+p^{w}}{r}\right\} \frac{\lambda p-p^{w}}{r} \geq 0
$$

where the last term is negative if the no-further-tax-competition condition holds. The inequality holds if the expression between brackets is negative too. In the brackets, the second term is obviously negative, while the first one is if

$$
\alpha_{0}-q+\frac{\tau_{j}-\tau_{i}}{\gamma} \frac{\lambda p+p^{w}}{r}<0
$$

Since $\tau_{j}-\tau_{i}<0$, a sufficient condition for the inequality to hold is that either

$$
\alpha_{0}-q+\frac{\tau_{j}-\tau_{i}}{\gamma} \frac{\lambda p}{r}<0
$$

or

$$
\alpha_{0}-q+\frac{\tau_{j}-\tau_{i}}{\gamma} \frac{p^{w}}{r}<0
$$

which means either $\alpha^{F A}-q<0$ or $\alpha^{q}-q<0$ : real investment is "enough mobile" to generate in Step 3 or in Step 6 of the game $\alpha<q$ although initially $\alpha_{0}>q$ - see the definition of "enough mobile" given above.

Lemma 4 If the no-further-tax-competition condition holds, $\tau_{j}-\tau_{i}<0$ and the move to CEFA characterized by $\lambda^{W W}$, then further increase in tax rates is aggregate welfare increasing.

Indeed, one can show that

$$
\frac{d W}{d \tau_{i}^{F A}}=(u-2 s) q \frac{p}{r}>0
$$

and

$$
\frac{d W}{d \tau_{j}^{F A}}=(u-2 s)(1-q) \frac{p}{r}>0
$$




\subsection{Tentative conclusion and illustration (I)}

We can conclude, tentatively, that the move from SA to C\&FA is aggregate welfare improving provided that the reform and formula are decided cooperatively in the joint best interest of the jurisdictions concerned; that formula will be characterized by a parameter $\lambda^{W W}$ compatible with a no-further-taxcompetition condition. Such a condition involves that the formula emphasizes criteria that the MJE can not easily manipulate and ensures that the reform will not boost tax competition. Therefore the choice of the formula is a key decision for the operation and the future of the system.

More formally, we can state

Proposition 5: In a two-jurisdiction - one-degree mobile MJE setting, where the MJE is "enough mobile", $\exists \lambda^{W W} \in[0,1]$ s.t. (1) $\lambda^{W W}=\arg \max W=$ $W_{i}+W_{j}$, (2) $\Delta W>0$ and the reform is adopted unanimously provided that side payments are possible, and (3) $\tau_{h}^{F A} \geq \tau_{h}^{q}, h=i, j$ so that, if it is adopted unanimously, the reform does not boost tax competition. Especially, when $\alpha_{0}>q>1 / 2,\left(\tau_{i}-\tau_{i}<0\right)$, for sure (1), (2) and (3) are compatible; then $\lambda^{W W}=0$.

To highlight that conclusion, suppose that jurisdiction $i$ is an old member state of the European Union and jurisdiction $j$ a new member state. Initial production and larger market share are located in $i$; production is mobile but market share is not, or at least is less mobile. Corporate tax rate is smaller in the new member state than in the larger. The move from SA to C\&FA will be welfare increasing for the two Member States considered together and no risk of further tax competition will appear, if the reform is adopted cooperatively with a formula which emphasizes the distribution of market shares, thus of sales on a destination principle ${ }^{8}$. Then, the old member state will individually gain in terms of social welfare and the new one will individually lose; however a side payment will be made from the old to the new member state. The no-further-tax-competition does not preclude tax competition at all; on the contrary the reform makes sense only if there is enough mobility of real investment and in particular if the production is extensively relocated in $j$ after its adhesion to the $\mathrm{EU}$, which is characterized by $\alpha<q$ while initially $\alpha_{0}>q$.

${ }^{8}$ If $\lambda^{W W}=0$ the $C \& F A$ is actually a tax on sales based on the destination principle. This is in line with the more general observation that using $C \& F A$ means taxing the factors behind the formula. 
In that example, emphasizing the distribution of sales both reduces the freedom of the MJE and forces it to pay the larger amount of taxes in the high tax jurisdiction; thus there are two arguments in favour $\lambda=0$. If, unlike that, the market share is larger in the new member state, then the optimal formula is characterized by a positive value of the parameter $\lambda$. However that parameter will have to fulfill the no-further-tax-competition condition.

Incidentally it is worth noticing that if both governments are Leviathan, the equilibrium formula will put more emphasis on sales since the authorities are less committed with respect to the welfare of the shareholders, whose best interest is to have a formula which favors the mobility of the firm, thus which emphasizes criteria that the MJE controls like the distribution of its investment and operation.

Now we will see if these results hold when more sophisticated strategies are permitted to the MJE.

\section{A two-degree mobile MJE}

In this section we assume that the MJE controls more than a single variable, in fact we assume it controls two variables. In Section 3.1 the additional variable under the control of the MJE is the origin of sales: the MJE is no longer bound to deliver $q$ in jurisdiction $i$ through its affiliate in that jurisdiction; instead it can decide to deliver a fraction $\nu$ of its output from the affiliate in $i$ to customers in both jurisdictions and to do so independent of the place of production of its output. Therefore the MJE controls two variables $\alpha$ and $\nu$. The use of a value of $\nu$ different from $q$ and $\alpha$ is a way of shifting taxable profits from one jurisdiction to another.

In Section 3.2, a third and lowest tax rate jurisdiction is introduced. The MJE may use a passive affiliate in that jurisdiction to ensure that as much as possible of its tax base is taxed in that jurisdiction. The MJE finances its real investment using funds partly channeled through the third jurisdiction and possibly converted from one type of finance to another - actually from shares to loan - there. Conversely, income from real activities is partly channeled through the affiliate in the passive jurisdiction, possibly taxed there and then turned from interest into dividends; these latter benefit from the application of the exemption principle in the jurisdiction of residence of the parent company (as mentioned above we assume that all the jurisdictions are located within the EU). 
In this section we assume that the set of jurisdictions forming the consolidating area coincides with the set of all jurisdictions; in that set the decision to adopt the reform is assumed to be taken unanimously. Unlike that, in Section 4, we will reconsider Section 3.2 to investigate what happens if the reform is only considered for adoption by the two active jurisdictions; then one jurisdiction remains outside the consolidating area.

In both Section 3.1 and Section 3.2, and in the sequel of the paper as well, we will pay attention to an important incentive compatibility constraint: tax shifting opportunities are only used by the MJE if they increase its value.

\subsection{Tax shifting and paper profit, a two-jurisdiction case}

Suppose that the MJE can decide not only on the distribution of its real investment, but also on the places where profits are reported. In other words, the assumption that in a given jurisdiction, say $i$, it is taxed on the sales to final consumers $q$ plus the sales to the other affiliate of the group $\alpha-q$ is relaxed. Instead it can sell to consumers in any jurisdiction through its affiliate in the local or foreign jurisdiction. Let $\nu$ the fraction of the MJE production sold from the entity in $i$. Both $\alpha$ and $\nu$ are now decision variables for the MJE which, formally, will consider moving from

$$
M J E_{0}=\left(\alpha_{0}, q, q\right) \in[0,1] \times[0,1] \times[0,1]
$$

to

$$
M J E=(\alpha, \nu, q) \in[0,1] \times[0,1] \times[0,1]
$$

to maximize its value $V$.

\subsubsection{Under SA}

Under Separate Accounting, the tax bases now are,

$$
\begin{aligned}
B_{i} & =\nu \frac{p}{r}+(\alpha-\nu) \frac{p^{w}}{r} \\
B_{j} & =(1-\nu) \frac{p}{r}-(\alpha-\nu) \frac{p^{w}}{r}
\end{aligned}
$$


in jurisdictions $i$ and $j$ respectively, with $\alpha$ and $\nu$ being the two variables under the control of the firm. Selection of $\nu$ smaller than $q$ generates an extra profit in the low tax jurisdiction $j$

$$
(q-\nu)\left(\frac{p}{r}-\frac{p^{w}}{r}\right)
$$

This is called a "paper profit" because it is not based on any real decision. We assume that pursuing paper profit has a cost - think of the risk that the operation is rejected by the tax authorities on the basis that it has no economic grounds - denoted by

$$
c(\nu)=\frac{\beta}{2}(\nu-q)^{2}, \beta<\gamma
$$

This cost is, however, smaller than that of moving real investment.

Let us then reconsider Steps 2 and 3 of the game.

At Step 3, maximizing the value of the firm w.r.t. the two variables under its control provides us with the equilibrium values,

$$
\alpha^{\nu}=\alpha_{0}+\frac{\tau_{j}-\tau_{i}}{\gamma} \frac{p^{w}}{r}
$$

- which is formally unchanged - and

$$
\nu=q+\frac{\tau_{j}-\tau_{i}}{\beta} \frac{p-p^{w}}{r}
$$

As a consequence, the indirect value of the firm becomes,

$$
\begin{aligned}
V^{\nu}= & \frac{p}{r}-\tau_{i}\left[\left(q+\frac{\tau_{j}-\tau_{i}}{\beta} \frac{p-p^{w}}{r}\right) \frac{p-p^{w}}{r}+\left(\alpha_{0}+\frac{\tau_{j}-\tau_{i}}{\gamma} \frac{p^{w}}{r}\right) \frac{p^{w}}{r}\right] \\
& -\tau_{j}\left[\left(1-q-\frac{\tau_{j}-\tau_{i}}{\beta} \frac{p-p^{w}}{r}\right) \frac{p-p^{w}}{r}+\left(1-\alpha_{0}-\frac{\tau_{j}-\tau_{i}}{\gamma} \frac{p^{w}}{r}\right) \frac{p^{w}}{r}\right] \\
& -\frac{\gamma}{2}\left(\frac{\tau_{j}-\tau_{i}}{\gamma} \frac{p^{w}}{r}\right)^{2}-\frac{\beta}{2}\left(\frac{\tau_{j}-\tau_{i}}{\beta} \frac{p-p^{w}}{r}\right)^{2}
\end{aligned}
$$

At Step 2, governments, maximizing the social welfare of their residents will now take into account the incentive compatibility constraint $V^{\nu} \geq V^{q}$ 
through a Lagrange multiplier $\mu$ with $\mu=0$ - Case 1 (unconstrained) when the incentive compatibility constraint is not bounded - and $\mu>0$ - Case 2 (constrained) when the constraint is bounded. Then they will decide on tax rates such that ${ }^{9}$

$\tau_{i}^{\nu}=\frac{u-s-\mu}{2 u-s-\mu}\left[\frac{q p+\left(\alpha_{0}-q\right) p^{w}}{\gamma\left(p-p^{w}\right)^{2}+\beta\left(p^{w}\right)^{2}} \gamma \beta r-\frac{p^{w} \beta}{\gamma\left(p-p^{w}\right)^{2}+\beta\left(p^{w}\right)^{2}} \frac{w}{u-s-\mu}+\tau_{j}^{\nu}\right]$

Under Case 1 (unconstrained), $\mu=0$ and equation (27) reduces to an expression similar to that in Section 2,

$$
\tau_{i}^{\nu}=\frac{u-s}{2 u-s}\left[\frac{q p+\left(\alpha_{0}-q\right) p^{w}}{\gamma\left(p-p^{w}\right)^{2}+\beta\left(p^{w}\right)^{2}} \gamma \beta r-\frac{p^{w} \beta}{\gamma\left(p-p^{w}\right)^{2}+\beta\left(p^{w}\right)^{2}} \frac{w}{u-s}+\tau_{j}^{\nu}\right]
$$

It can be shown that the intercept of equation (28) is smaller than the intercept of equation (8) so that the race to the bottom is expected to be stronger when the firm is two-degree mobile than one it is only one-degree mobile. Termed otherwise,

$$
\tau_{i}^{\nu}=M^{\nu} \tau_{i}^{q}, \tau_{j}^{\nu}=M^{\nu} \tau_{j}^{q}
$$

An important consequence is that

$$
\tau_{j}^{\nu}-\tau_{i}^{\nu}=M^{\nu}\left(\tau_{j}^{q}-\tau_{i}^{q}\right)<\tau_{j}^{q}-\tau_{i}^{q}
$$

with

$$
M^{\nu}=\frac{\beta\left(p^{w}\right)^{2}}{\gamma\left(p-p^{w}\right)^{2}+\beta\left(p^{w}\right)^{2}}<1
$$

Then $\tau_{h}^{\nu}<1, h=i, j$. Using equations (4) and (24), the investment in jurisdiction $i$ is

$$
\alpha^{\nu}=\alpha_{0}+M^{\nu} \frac{\tau_{j}^{q}-\tau_{i}^{q}}{\gamma} \frac{p^{w}}{r}
$$

which departs less from from $\alpha_{0}$ than under a single degree of MJE mobility, $\alpha^{q}$.

It turns out that a two-degree mobile MJE invests less in the low tax jurisdiction, substituting a less costly paper profit for a costly move of real investment.

\footnotetext{
${ }^{9}$ From the first derivative of $L=W^{\nu}-\mu\left(V^{q}-V^{\nu}\right)$ w.r.t. $\tau_{i}$.
} 
Since both the equilibrium tax rates and the costs of optimizing the location of the production and that of sales are smaller than in Section 2 above, the incentive compatibility constraint is satisfied. Therefore Case 2 (constrained) does not need to be investigated.

Finally, in terms of social welfare, this situation is worse than that of Section 2: $W^{v}<W^{q}$. Indeed

$$
\begin{aligned}
& \quad(u-2 s) M^{\nu}\left[\left(\tau_{j}^{q}-\tau_{i}^{q}\right)\left(\frac{q\left(p-p^{w}\right)+\alpha_{0} p^{w}}{r}\right)+\tau_{j}^{q} \frac{p}{r}\right] \\
& +(u-s)\left(M^{\nu}\right)^{2}\left(\tau_{j}^{q}-\tau_{i}^{q}\right)^{2}\left[\frac{1}{\beta}\left(\frac{p-p^{w}}{r}\right)^{2}+\frac{1}{\gamma}\left(\frac{p^{w}}{r}\right)^{2}\right] \\
& <(u-2 s)\left[\left(\tau_{j}^{q}-\tau_{i}^{q}\right)\left(\frac{q\left(p-p^{w}\right)+\alpha_{0} p^{w}}{r}\right)+\tau_{j}^{q} \frac{p}{r}\right] \\
& +(u-s)\left(\tau_{j}^{q}-\tau_{i}^{q}\right)^{2} \frac{1}{\gamma}\left(\frac{p^{w}}{r}\right)^{2}
\end{aligned}
$$

\subsubsection{Move to C\&FA}

Should the tax system then moves to C\&FA, what will the effect be on the value and behavior of the firm, the apportionment formula and social welfare, and the possible tax competition?

In fact the reform generates the same outcomes as under Section 2.2 above: paper profit disappears and the MJE loses the additional value they possibly provided. Unlike the firm, the governments will now recoup the corresponding revenue loss: they jointly gain from the reform, and the gain may be larger than in the previous setting.

Two results deserve our attention, they are summarized in the proposition thereafter

Proposition 6 Compared to a two-jurisdiction-one-degree mobile MJE setting, in a two-jurisdiction - two-degree mobile MJE setting, where the MJE is "enough mobile", (1) the no-further-tax-competition condition is less severe and (2) the aggregate welfare gain involved by the move from $S A$ to CESFA is larger.

The first part of the proposition comes from the observation that $\lambda p<p^{w}$ is a sufficient condition for $\tau_{h}^{F A} \geq \tau_{h}^{q}, h=i, j$ to hold. Since $\tau_{h}^{q}>\tau_{h}^{\nu}$, it is a fortiori a sufficient condition for $\tau_{h}^{F A} \geq \tau_{h}^{q}$. Moreover, now, it is possible to 
have the no-further-tax-competition condition holding for values of $\lambda>p^{w} / p$. The second part of the proposition is based on equation (32): since under the conditions derived at Section $2, W^{F A}>W^{q}$, then $W^{q}>W^{\nu}$ implies $W^{F A}-W^{\nu}>W^{F A}-W^{q}$.

\subsection{Profitable detour through a third jurisdiction}

So far we have limited the economy to two jurisdictions. We will now introduce a third one. Among those jurisdictions, two are said to be active because the MJE has or can have active entities producing goods and services on their territory or selling them from their territory. This is the situations of jurisdictions $i$ and $j$ already considered. The additional jurisdiction $k$ is said passive. It offers the lowest tax rate, $\tau_{k}<\min \left(\tau_{i}, \tau_{j}\right)$, and is only used for the purposes of the taxation of income, through a lucrative detour and intermodal financing. Notice that $k$ can be a specific legal or geographical space located within either $i$ or $j$. Nevertheless, jurisdiction $k$ is not considered by $i$ and $j$ as a tax heaven. This assumption, in line with EU practice provided that $k$ belongs to the EU, is important; if it did not hold, benefits repatriated from $k$ to the parent jurisdiction would not benefit of the exemption mechanism deemed to be at work in that economy.

Profits from both active entities, up to a fraction $c$, are channeled to jurisdiction $k$ to be taxed there - due to the necessity of avoiding thin capitalization, that strategy is limited to a fraction $c$ of the investment (we deliberately use the same letter as in Mintz and Smart, 2004, who allow for a similar phenomenon). We assume that using intermodal financing and the lucrative detour has a cost; however to avoid unnecessary complication in the exposition, we suppose that cost such that

$$
\begin{aligned}
c(c) & =0, c \leq \overline{c_{i}}=\overline{c_{j}} \\
& \rightarrow \infty, c>\overline{c_{i}}=\overline{c_{j}}
\end{aligned}
$$

where $\overline{c_{i}}, \overline{c_{j}}$ stand for the upper bound to the indebtedness of the local affiliates; beyond those threshold, interest is considered as a hidden dividend and is no longer deductible against the tax base in the paying jurisdiction.

More formally, the MJE considers moving the structure of its financing and location of the bulk of its tax base from

$$
M J E_{0}=\left(\alpha_{0}, 0, q\right) \in[0,1] \times[0,1] \times[0,1]
$$


to

$$
M J E=(\alpha, c, q) \in[0,1] \times[0,1] \times[0,1]
$$

in order to maximize its value $V$.

\subsubsection{Under Separate Accounting}

The tax bases in the three jurisdictions are respectively, from equation (2)

$$
\begin{aligned}
B_{i}^{c} & =(1-c) B_{i}=(1-c)\left[q \frac{p}{r}+(\alpha-q) \frac{p^{w}}{r}\right] \\
B_{j}^{c} & =(1-c) B_{i}=(1-c)\left[(1-q) \frac{p}{r}-(\alpha-q) \frac{p^{w}}{r}\right] \\
B_{k} & =c \frac{p}{r}
\end{aligned}
$$

Now, at Step 3 of the game, maximizing the value of the MJE provides a new expression for the fraction of the real investment in $i$

$$
\alpha^{c}=\alpha_{0}+\frac{\tau_{j}-\tau_{i}}{\gamma}(1-c) \frac{p^{w}}{r}
$$

with $c=\overline{c_{i}}=\overline{c_{j}}$.

Comparing equation (35) with equation (5) we immediately see that the sensitivity of the investment location is reduced, and is in fact limited to the fraction not taxed in the active entities. In the extreme case where the financing through a loan from $k$ has no upper limit, the MJE will not relocate its real investment for tax purposes. The reasoning for the MJE is simple: why to undertake a costly real investment relocation when a free tax shifting opportunity exists?

At Step 2, we need again to introduce the incentive compatibility constraint explicitly ${ }^{10}$, and then to make the same distinction as above. Now the Lagrange multiplier $\mu$ vanishes if $\tau_{i}^{c}$ is such that $V^{c} \geq V^{q}$ and is positive otherwise. We also require as previously that $0<\tau_{i}^{c}<1$.

It turns out that the reaction function now becomes

$$
\tau_{i}^{c}=\frac{u-s-\mu}{2 u-s-\mu}\left[\frac{q p+\left(\alpha_{0}-q\right) p^{w}}{(1-c)\left(p^{w}\right)^{2}} \gamma r-\frac{1}{u-s-\mu} \frac{w}{(1-c) p^{w}}+\tau_{j}^{c}\right]
$$

\footnotetext{
${ }^{10}$ The Lagrangian is $L=W^{c}-\mu\left(V^{q}-V^{c}\right)$.
} 
Case 1. Suppose first that the constraint is not bounded. Then $\mu=0$. That case is in line with the way we have treated Step 2 so far and the reaction functions are of the type

$$
\tau_{i}^{c}=\frac{u-s}{2 u-s}\left[\frac{q p+\left(\alpha_{0}-q\right) p^{w}}{(1-c)\left(p^{w}\right)^{2}} \gamma r-\frac{1}{u-s} \frac{w}{(1-c) p^{w}}+\tau_{j}^{c}\right]
$$

Comparing equations (37) and (8), we see that tax competition is less severe in the present setting: the intercept is higher and so are the values of the tax rates at Nash equilibrium.

More precisely, in the new situation,

$$
\tau_{h}^{c}=M^{c} \tau_{h}^{q}, h=i, j
$$

with

$$
M^{c}=\frac{1}{1-c}>1
$$

and

$$
\alpha^{c}=\alpha_{0}+M^{c} \frac{\tau_{j}^{q}-\tau_{i}^{q}}{\gamma}(1-c) \frac{p^{w}}{r}=\alpha^{q}
$$

Therefore the distribution of the location of investment and production is unaffected although the place where income is taxed is affected.

However, two problems arise then. First though $\tau_{h}^{q}<1$, there is no guarantee that $\tau_{h}^{q} /(1-c)$ will be.

Second, if the tax rates are determined by reaction functions like equation (37), the tax liabilities of the MJE w.r.t. the two active jurisdictions are unchanged compared to the situation with only two jurisdictions, thus $\tau_{h}^{c} B_{h}^{c}=\tau_{h}^{q} B_{h}$; but then the MJE has to pay taxes to jurisdiction $k$ too except if $\tau_{k}=0$-, so that it has no incentive to channel funds through that jurisdiction. This means that the active jurisdictions have fully anticipated the outflow of tax base and corrected accordingly the tax rates, but then the incentive compatibility constraint is not satisfied and the problem under investigation loses its relevance. We can also regard that case as one of symmetric information: the tax authorities of the active jurisdictions know that the MJE considers tax shifting through the detour.

Due to the observations above, the tax rates need to be reduced by a factor $h$, with $0<h<1$ and the investigation of Case 2 is relavant.

Case 2. Suppose now that the incentive compatibility constraint is bounded. The overall tax liabilities of the firm are actually reduced and the equilibrium 
tax rates are smaller than in Case 1. Among the values of the tax rates in the active entities consistent with that requirement, let us focus on $\tau_{h}^{c}=\tau_{h}^{q}$, assuming $h=1-c$. In that case the incentive compatibility constraint is satisfied and $\mu>0$. That case means assuming asymmetric information: the tax authorities of the active jurisdiction do not know that the MJE considers the tax shifting opportunity or, equivalently, they cannot push up their corporate tax rates despite the new information that a profitable detour is possible, e.g. because the same corporate tax rate is also used for taxing domestic firms. In that case,

$$
\alpha^{c}=\alpha_{0}+\frac{\tau_{j}^{q}-\tau_{i}^{q}}{\gamma}(1-c) \frac{p^{w}}{r}
$$

which departs less from initial position $\alpha_{0}$.

\subsubsection{C\&FA applied by the three jurisdictions}

The first and main implication of the adoption of C\&FA by all three jurisdictions is that $c$ vanishes since the inflow in the entity located in $k$ is cancelled by the corresponding outflow. Then $c=0$ under C\&FA and the distribution of investment between the two active jurisdictions is again given by equation (10). Thus the maximization of the value of the MJE at Step 6 leaves us again with

$$
\alpha^{F A}=\alpha_{0}+\frac{\tau_{j}-\tau_{i}}{\gamma} \frac{\lambda p}{r}
$$

And again, from Step 5, the equilibrium tax rates obey the reaction functions like (13)

$$
\tau_{i}^{F A}=\frac{u-s}{2 u-s}\left[\frac{\lambda \alpha_{0}+(1-\lambda) q}{\lambda^{2} p} \gamma r-\frac{1}{u-s} \frac{w}{\lambda p}+\tau_{j}^{F A}\right]
$$

to be compared with equation (37) - Case 1 - or (8) - Case 2 - to determine a sufficient no-further-tax-competition condition. In the former case, that condition is now

$$
\lambda p<(1-c) p^{w}
$$

less likely to be fulfilled than its counterpart in the latter case,

$$
\lambda p<p^{w}
$$


as previously. Especially, if $c$ is close to unity - no thin capitalization rule in either $i$ or $j$-, the simplest way to satisfy that condition will be to set $\lambda$ equal to 0 ; however thin capitalization are under the authority of local jurisdictions.

Finally, at Step 4, we determine the equilibrium value of $\lambda$, again provided by equations (18) and (19).

The reform will be adopted at unanimity if there is an aggregate welfare gain

$$
\begin{aligned}
& 2 s \frac{p}{r}+(u-2 s)\left(\tau_{i}^{F A} B_{i}^{F A}+\tau_{i}^{F A} B_{i}^{F A}\right)-2 s c\left(\alpha^{F A}-\alpha_{0}\right)^{2} \\
\geq & 2 s \frac{p}{r}+(u-2 s)\left[(1-c)\left(\tau_{i}^{c} B_{i}^{q}+\tau_{j}^{c} B_{j}^{q}\right)+c \tau_{k} \frac{p}{r}\right]-2 s c\left(\alpha^{c}-\alpha_{0}\right)^{2}
\end{aligned}
$$

Then high tax jurisdiction $j$ will gain social welfare and will be able to offset both jurisdictions $i$ and $k$; indeed, by losing its revenue, that latter loses all its welfare since nothing is produced nor sold on its territory.

Consider the two cases examined above. In Case $1-\tau_{h}^{c}=\tau_{h}^{q} /(1-c)-$ the inequality above reduces to

$$
W^{F A}-W^{q}>-2 s c \tau_{k} \frac{p}{r}
$$

less severe than previously - $W^{F A}-W^{q}>0$ - the right hand side of the inequality corresponding to the gain of value of the MJE no longer compelled to pay tax to its passive low tax entity; that result sets forth the lack of relevance of that Case 1 since then the MJE had no incentive to decide for the detour.

In Case 2 - especially $\tau_{h}^{c}=\tau_{h}^{q}$ - , that condition becomes

$$
W^{F A}-W^{q}>(u-2 s) c\left[\tau_{k} \frac{p}{r}-\tau_{i}^{q} B_{i}^{q}+\tau_{j}^{q} B_{j}^{q}\right]
$$

where the term between brackets in the right hand side of the inequality is necessarily negative $-B_{i}^{q}+B_{j}^{q}=p / r$ and $\tau_{k}<\min \left(\tau_{i}^{q}, \tau_{j}^{q}\right)$ : the active jurisdictions, by eliminating the effect of the detour on their tax bases, get back the revenues previously lost in favor of jurisdiction $k$; despite they have to transfer revenue to jurisdiction $k$ to compensate its own tax revenue loss, some surplus revenue remains their.

It turns out that, defining $J$ as the set of jurisdictions and $A$ as the set of jurisdictions participating to the consolidating area, 
Proposition 7 : In a three-jurisdiction - two-degree mobile MJE setting, where the MJE is "enough mobile" and where $A=J, \exists \lambda^{W W} \in[0,1]$ s.t. (1) $\lambda^{W W}=\arg \max W=W_{i}+W_{j}$ given $W_{k}^{c}$, (2) $\Delta W>0$ and the reform is adopted unanimously provided that side payments are possible, and (3) $\tau_{h}^{F A} \geq \tau_{h}^{c}, h=i, j$ so that, if it is adopted unanimously, the reform does not boost tax competition. Especially, when $\alpha_{0}>q>1 / 2,\left(\tau_{i}-\tau_{i}<0\right)$, for sure (1), (2) and (3) are compatible; then $\lambda^{W W}=0$.

\subsection{Tentative conclusion and illustration (II)}

Section 3.1 shows that an increased freedom of the MJE with respect to tax authorities, within a given geographic area, allowing it to set up tax shifting and paper profit strategies, provides us with a further argument in favor of adopting C\&FA. We have limited the investigation to a single such strategy but it could be repeated with other ones like the determination of the size of transfer prices or of the level of royalties and various kinds of management fees.

Section 3.2 allows us to look at situations like the adoption of C\&FA in a heterogeneous federation in terms of corporate tax rates. This is actually the case in the EU where those rates can be as small as 12.5 per cent in Ireland, and even less in Belgian Coordination Centres, and as high as 38 per cent in Germany (IFS data for 2005). We have shown that the reform can be aggregate welfare increasing in such a setting enabling jurisdictions which gain welfare to compensate those who lose, including financial centres, through side payments. Especially, in the asymmetric case 2, by eliminating the effect of the detour on their tax bases, the active jurisdictions get back the revenues previously lost in favor of jurisdiction $k$; since their tax rates are higher, that allows them to transfer enough revenue to jurisdiction $k$ to compensate that jurisdiction's loss of tax revenue.

\section{A sub- or open federation}

In Section 3.2 above we assumed that the three jurisdictions adopted the reform together. Now let us imagine that only two of them, the two active ones, decide to introduce the reform, forming a Sub-Federation, while jurisdiction $k$ decides to stay outside the consolidating area. 
Such a situation is possible in the EU if the two active jurisdictions decide to nest their joint decision within an Enhanced Cooperation Agreement (Bordignon and Busco, 2006).

This is also the case if the Federation is open to the rest of the world; then we need to reinterpret jurisdiction $k$ of Section 3.2 as the rest of the world, assuming however that fiscal relations with that rest of the world are ruled by an actual application of the exemption principle. We will see however that reconsidering the use of the exemption principle can be a useful tax base protection device for the consolidating area.

\subsection{Enhanced Cooperation between the active juris- dictions}

Suppose now that jurisdictions $i$ and $j$ decide to implement C\&FA, while $k$ remains outside the consolidating area. Then the tax bases respectively are

$$
\begin{aligned}
B_{i} & =[\lambda \alpha+(1-\lambda) q](1-c) \frac{p}{r} \\
B_{j} & =[\lambda(1-\alpha)+(1-\lambda)(1-q)](1-c) \frac{p}{r} \\
B_{k} & =c \frac{p}{r}
\end{aligned}
$$

and, at Step 6, the firm decides for

$$
\alpha^{F A 2 / 3}=\alpha_{0}+\frac{\tau_{j}-\tau_{i}}{\gamma}(1-c) \frac{\lambda p}{r}
$$

In Step 5, the determination of the tax rates requires the use of a Lagragian and the same distinction as above between a Case 1 and a Case 2.

The reaction function becomes

$$
\tau_{i}^{F A 2 / 3}=\frac{u-s-\mu}{2 u-s-\mu}\left[\frac{\lambda \alpha_{0}+(1-\lambda) q}{\lambda^{2}(1-c) p} \gamma r-\frac{1}{u-s-\mu} \frac{w}{\lambda(1-c) p}+\tau_{j}^{F A}\right]
$$

Case 1. Under Case 1, $\mu=0$ and

$$
\tau_{i}^{F A 2 / 3}=\frac{u-s}{2 u-s}\left[\frac{\lambda \alpha_{0}+(1-\lambda) q}{\lambda^{2}(1-c) p} \gamma r-\frac{1}{u-s} \frac{w}{\lambda(1-c) p}+\tau_{j}^{F A}\right]
$$


whose intercept is larger than if the reform had been adopted unanimously, at least for identical values of $\lambda$. Then $\tau_{h}^{F A 2 / 3}=\tau_{h}^{F A} /(1-c)$ which means that tax competition is less likely to appear than in the situation investigated in Section 3.2, a result which parallels the attenuation of tax competition already observed under SA in the same context. Comparison of $\tau_{h}^{F A 2 / 3}=\tau_{h}^{F A} /(1-c)$ with $\tau_{h}^{c}=\tau_{h}^{q} /(1-c)$ involves that the no further tax competition condition is now the same as in the one-degree mobile MJE setting, $\lambda p<p^{w}$, obtained from a comparison of equations (37) and (44). Then $\alpha^{F A 2 / 3}=\alpha^{q}$ and the reform has no effect on the real decision of the MJE. Finally $\lambda^{W}$ is determined at Step 4 as previously and the same condition as in Section 2 applies for the adoption of the reform, by the three consolidating jurisdictions, unanimously. However the same two problems as under Section 3.2. arise; there is no guarantee that $\tau_{h}^{F A 2 / 3}$ is not larger than one and the incentive compatibility constraint is not satisfied.

Case 2. Therefore let us reduce $\tau_{h}^{F A 2 / 3}$ with a factor $h$ such that $0<h<1$ and consider especially $h=1-c$. Then $\tau_{h}^{F A 2 / 3}=\tau_{h}^{F A}$ as previously $\tau_{h}^{c}=\tau_{h}^{q}$. The no-further-tax-competition is again $\lambda p<p^{w}$, and $\alpha^{F A 2 / 3}$ is determined by equation (42) accordingly. Finally $\lambda^{W}$ is decided cooperatively by the two active jurisdictions provided that they decide to move to C\&FA. That is the case if

$$
W^{F A}-W^{q}>0
$$

That condition is more demanding than the corresponding one (40) since the active jurisdictions no longer get back the profit shifted by the MJE to its passive entity.

\subsection{Tax base protection in the consolidating area}

Let us focus on Case 2. The adoption of the reform either within a SubFederation, e.g. through an Enhanced Cooperation Agreement within the EU, rather than by the whole Federation, or within an open Federation, i.e. a Federation which does not exhaust the entire economy, formally in a framework characterized by $A=\{i, j\} \subset J=\{i, j, k\}$, implies a loss of tax revenue for the consolidating area which amounts to

$$
\left[\left(\tau_{i}^{F A}-\tau_{k}\right) c B_{i}^{F A}+\left(\tau_{j}^{F A}-\tau_{k}\right) c B_{j}^{F A}\right] \frac{p}{r}
$$

The consolidating area could recoup that revenue loss by simultaneously adopting another tax reform. That latter consists to give up the exemption 
principle w.r.t. dividends coming from entities located in jurisdictions outside the consolidating area and to adopt instead the crediting principle - see the US system where crediting applies to dividends from outside the US. Then, at given tax rates in the consolidating area, the MJE has no longer incentive to channel its income through the passive entity $k$.

To face the possibility that the MJE decides not for channelling through $k$ but for accumulating income in that affiliate, used as the instrument for financing further investment anywhere in the economy, the move to crediting could be accompanied by the adoption of a measure allowing the consolidating area to levy tax on profits located outside its territory, with a credit for local tax. Such measure often exists in anti-cfc legislations. Termed outside, that measure means extending the consolidated tax base to worldwide profits of the MJE wherever they are located, within or outside entities participating to the consolidating area, and irrespective whether or not they are repatriated to the consolidating area; and to give a credit for taxes paid outside the consolidating area.

\subsection{Tentative conclusion and illustration (III)}

Given the analysis conducted so far in this Section, it turns out that

Proposition 8 : Proposition 7 also holds in a three-jurisdiction-two-degree mobile MJE setting, where the MJE is "enough mobile" and where $A=$ $\{i, j\} \subset J=\{i, j, k\}$, if the consolidating area, when moving from $S A$ to CEFA, completes the reform by giving up the exemption principle for dividends coming from outside the area, adopting instead the crediting principle, and extending its application to profits not repatriated to entities belonging to the consolidating area.

To illustrate imagine that the founding members of the European Union and maybe some other countries, would like to go ahead with EU integration and to adopt C\&FA within an Enhanced Cooperation Agreement. Proposition 8 suggests that when they move to $\mathrm{C} \& \mathrm{FA}$, those countries simultaneously replace the exemption mechanism by the crediting one for foreign dividends and repatriated profits, what is permitted by the European Directive on cross border dividends between parent companies, and extend taxation and crediting to non-repatriated profits; that last measure can take the form of taxing accrued capital gains with a credit for the tax levied abroad on the upstream profit. 


\section{Conclusion}

In this paper, we have investigated a move from Separate Accounting to Consolidation and Formulary Apportionment, with the reform suggested by the EU Commission in 2001 especially in mind. In this exercise we have focused the investigation on two related issues, the choice of the formula and the composition of the consolidating area - either the entire EU or some Member States within an Enhanced Cooperation Agreement -, and their impact on social welfare and tax competition.

In Section 2 we considered a one-degree mobile MJE allowed to decide on the location of its investments and production plants, and two jurisdictions where that MJE might be active. In that setting we developed a six-step game which in some sense parallels the development of the European Union. The first three steps correspond to the pre-reform period, the last three to today's situation, with the jurisdictions deciding cooperatively whether or not to adopt the reform, and deciding non-cooperatively on the tax rates they will apply after its implementation.

In this context we derived the range of values of the apportionment formula consistent with no further development of tax competition after the adoption of the reform and checked that its application actually increased the social welfare of the consolidation area, allowing the winning jurisdiction to offset the losses of the losing through a side payment.

Thereafter we reconsidered those results in more sophisticated cases. In Section 3, we allowed the MJE to be two-degree mobile, also being permitted either to decide on the origin of its sales or to use an intermodal financing strategy and profitable detours for its flows of funds. In the latter case we introduced a third and passive jurisdiction, assuming that that jurisdiction needs to join the consolidating area in case of adoption of the reform.

In Section 4 we discussed the adoption of the reform by a Sub-Federation, a subset of EU Member States through an Enhanced Cooperation Agreement mechanism, or by a open Federation. This situation is of especially interest, since it corresponds to a possible device within the EU and also to the relationship between an EU-wide consolidating area and the rest of the world.

Our tentative policy conclusion is that the reform should be supported provided that (1) the formula puts emphasis on criteria that the MJE can not easily manipulate; (2) real investment is enough mobile; (3) the consolidation is made compulsory within the consolidating area; and (4) the consolidating area protects its capacity to actually levy taxes by adopting a crediting 
system, possibly extended to accrued capital gains, vis-à-vis the rest of the world. This final recommendation is valid even if the reform is adopted by the entire EU, as long as the EU remain connected to the rest of the world.

This paper paves the way for further research on coalitions and decision mechanisms within a bottom-up federation in progress, as well as the study of the consequences of tax policy changes by a group of jurisdictions sharing private actors, such as MJE's, with the rest of the world.

\section{REFERENCES}

Boadway, R. and N. Bruce, 1984, Welfare Economics, Blackwell.

Bordignon, M. and S. Busco, 2006, "On Enhanced Cooperation", Journal of Public Economics, in press.

European Commission, 2001, Company Taxation in the Internal Market, SEC(2001) 1681, Oct. 23, 2001.

European Commission, 2003, An Internal Market without Company Tax Obstacles, Achievements, Ongoing Initiatives and Remaining Challenges, $\mathrm{COM}(2003) 726$ final, Brussels.

Eichner, T. and M. Runkel, 2006, "Why the European Union Should Adopt Formula Apportionment with Double Sales?", mimeo, LM Univeristy, Munich.

Eggert W. and G. Schjelderup, 2003, "Symmetric tax competition under formula apportionment", Journal of Public Economic Theory, 5, 437-444.

Gérard, M, 2003, "L'imposition des entreprises multinationales en Europe, à propos d'un rapport de la Commission européenne", Revue Economique, 54 (3), pp. 489-498.

Gérard, M, 2005a, "Multijurisdictional firms and governments' strategies under alternative tax designs", CESifo WP, 1527, Munich.

Gérard, M., 2005b, "The Challenge of Taxing Multijurisdictional Companies in Europe", Tax Notes Int'l, 40 (13), December 26, pp. 1169-1173.

Gérard, M. 2006a, "A Closer Look at Belgium's Notonal Interest Deduction", Tax Notes Int'l, 41 (5), February, 6, pp. 449-453 (available on line in Worldwide Tax Daily, Tax Analysts, February, 8).

Gérard, M. 2006b, "Belgian moves to Dual Allowance of Corporate Equity", European Taxation, 4, pp 156-162.

Gérard, M. and J. Weiner, 2003, "Cross-border loss offset and formulary apportionment: How do they affect multijurisdictional firm investment 
spending and interjurisdictional tax competition?", CESifo WP, 1004, Munich.

Gérard, M. and J. Weiner, 2005, "Comment la compensation internationale des pertes et la répartition proportionnelle des revenus imposables peuvent affecter les choix des multinationales et la concurrence fiscale", Economie et Prévision, 173, forthcoming.

Goolsbee A. and E. Maydew, 2000, "Coveting thy neighbor's manufacturing: the dilemma of state income apportionment", Journal of Public Economics, $75,125-143$.

Gordon, R. and J. Wilson, 1986, "An examination of multijurisdictional corporate income taxation under formula apportionment", Econometrica, 54, $1357-1373$.

Hellerstein, W. and C. McLure, 2004, "The European Commission's Report on Company Income Taxation: What the EU Can Learn from the Experience of the US States", International Tax and Public Finance, 11, 199-220.

Martens-Weiner, J., 2006, Company Tax Reform in the European Union: Guidance from the United States and Canada on Implementing Formulary Apportionment in the EU, Springer Science + Business Media, New York.

Mintz, J. and M. Smart, 2004, "Income shifting, investment, and tax competition: Theory and evidence from provincial taxation in Canada", Journal of Public Economics, 88, 1149-1168.

Mintz, J. and A. Weichenrieder, 2005, "Taxation and the Financial Structure of German Outbound FDI", CESifo Working Paper, 1612, Munich.

Mongrain, S., N. Marceau and J. Wilson, 2006, Capital Tax Competition and the Emergence of Low Tax Countries, a paper presented at the Journées Louis-André Gérard-Varet, Marseille.

Nielsen S., P. Raimondos-Moller P. and G. Schjelderup, 2003, "Formula apportionment and transfer pricing under oligopolistic competition", Journal of Public Economic Theory, 5, 419-437.

OECD, 1996, Model Tax Convention on Income and on Capital, condensed version, Oecd, Paris.

Sorensen, P., 2004, "Company tax reform in the European Union", International Tax and Public Finance, 11, 91-115.

Pethig, R. and A. Wagener, 2003, "Profit Tax Competition and Formula Apportionment", CESifo Working Paper, 1010, Munich.

Riedl, N. and M. Runkel, 2006, "Company Tax Reform with a Water's Edge", CESifo Network meeting in Public Sector Economics. 
Slemrod, J. and J. Wilson, 2006, "Tax Competition with Parasitic Tax Havens", NBER Working Paper Series, 12225.

UNICE, 2000, "Memorandum on cross border company taxation obstacles in the single market", Unice, Brussels.

Weiner, J., 2002, "Would Introducing Formula Apportionment in the European Union Be a Dream Come True or the EU's Worst Nightmare?", Ifo Studien, 48, 419-432.

Weiner, J., 2005, "Formulary Apportionment and Group Taxation in the European Union: Insights From the United States and Canada", Taxation Papers, 8, EU Commission, DG Taxation and Customs Union.

Weiner, J., and M. Gérard, 2004, "Cross border loss offset, uncertainty, and formulary apportionment: A contribution to the European debate on the taxation of multinationals", Proceedings of the National Tax Association, 2003, 360-366.

Wellisch, D., 2004, "Taxation under Formula Apportionment - Tax Competition, Tax Incidence, and the Choice of Apportionment Factors", Finanzarchiv, 60, 24-41.

Weichenrieder, A., 2006a, "What determines the Use of Holding Companies and Ownership Chains?", mimeo.

Weichenrieder, A., 2006b, "Profit shifting in the EU: Evidence from Germany", mimeo. 


\title{
CESifo Working Paper Series
}

\author{
(for full list see www.cesifo-group.de)
}

1800 Øystein Foros and Hans Jarle Kind, Do Slotting Allowances Harm Retail Competition?, September 2006

1801 Tobias Lindhe and Jan Södersten, The Equity Trap, the Cost of Capital and the Firm's Growth Path, September 2006

1802 Wolfgang Buchholz, Richard Cornes and Wolfgang Peters, Existence, Uniqueness and Some Comparative Statics for Ratio- and Lindahl Equilibria: New Wine in Old Bottles, September 2006

1803 Jan Schnellenbach, Lars P. Feld and Christoph Schaltegger, The Impact of Referendums on the Centralisation of Public Goods Provision: A Political Economy Approach, September 2006

1804 David-Jan Jansen and Jakob de Haan, Does ECB Communication Help in Predicting its Interest Rate Decisions?, September 2006

1805 Jerome L. Stein, United States Current Account Deficits: A Stochastic Optimal Control Analysis, September 2006

1806 Friedrich Schneider, Shadow Economies and Corruption all over the World: What do we really Know?, September 2006

1807 Joerg Lingens and Klaus Waelde, Pareto-Improving Unemployment Policies, September 2006

1808 Axel Dreher, Jan-Egbert Sturm and James Raymond Vreeland, Does Membership on the UN Security Council Influence IMF Decisions? Evidence from Panel Data, September 2006

1809 Prabir De, Regional Trade in Northeast Asia: Why do Trade Costs Matter?, September 2006

1810 Antonis Adam and Thomas Moutos, A Politico-Economic Analysis of Minimum Wages and Wage Subsidies, September 2006

1811 Guglielmo Maria Caporale and Christoph Hanck, Cointegration Tests of PPP: Do they also Exhibit Erratic Behaviour?, September 2006

1812 Robert S. Chirinko and Hisham Foad, Noise vs. News in Equity Returns, September 2006

1813 Oliver Huelsewig, Eric Mayer and Timo Wollmershaeuser, Bank Behavior and the Cost Channel of Monetary Transmission, September 2006 
1814 Michael S. Michael, Are Migration Policies that Induce Skilled (Unskilled) Migration Beneficial (Harmful) for the Host Country?, September 2006

1815 Eytan Sheshinski, Optimum Commodity Taxation in Pooling Equilibria, October 2006

1816 Gottfried Haber and Reinhard Neck, Sustainability of Austrian Public Debt: A Political Economy Perspective, October 2006

1817 Thiess Buettner, Michael Overesch, Ulrich Schreiber and Georg Wamser, The Impact of Thin-Capitalization Rules on Multinationals' Financing and Investment Decisions, October 2006

1818 Eric O’N. Fisher and Sharon L. May, Relativity in Trade Theory: Towards a Solution to the Mystery of Missing Trade, October 2006

1819 Junichi Minagawa and Thorsten Upmann, Labor Supply and the Demand for Child Care: An Intertemporal Approach, October 2006

1820 Jan K. Brueckner and Raquel Girvin, Airport Noise Regulation, Airline Service Quality, and Social Welfare, October 2006

1821 Sijbren Cnossen, Alcohol Taxation and Regulation in the European Union, October 2006

1822 Frederick van der Ploeg, Sustainable Social Spending in a Greying Economy with Stagnant Public Services: Baumol’s Cost Disease Revisited, October 2006

1823 Steven Brakman, Harry Garretsen and Charles van Marrewijk, Cross-Border Mergers \& Acquisitions: The Facts as a Guide for International Economics, October 2006

1824 J. Atsu Amegashie, A Psychological Game with Interdependent Preference Types, October 2006

1825 Kurt R. Brekke, Ingrid Koenigbauer and Odd Rune Straume, Reference Pricing of Pharmaceuticals, October 2006

1826 Sean Holly, M. Hashem Pesaran and Takashi Yamagata, A Spatio-Temporal Model of House Prices in the US, October 2006

1827 Margarita Katsimi and Thomas Moutos, Inequality and the US Import Demand Function, October 2006

1828 Eytan Sheshinski, Longevity and Aggregate Savings, October 2006

1829 Momi Dahan and Udi Nisan, Low Take-up Rates: The Role of Information, October 2006

1830 Dieter Urban, Multilateral Investment Agreement in a Political Equilibrium, October 2006 
1831 Jan Bouckaert and Hans Degryse, Opt In Versus Opt Out: A Free-Entry Analysis of Privacy Policies, October 2006

1832 Wolfram F. Richter, Taxing Human Capital Efficiently: The Double Dividend of Taxing Non-qualified Labour more Heavily than Qualified Labour, October 2006

1833 Alberto Chong and Mark Gradstein, Who’s Afraid of Foreign Aid? The Donors' Perspective, October 2006

1834 Dirk Schindler, Optimal Income Taxation with a Risky Asset - The Triple Income Tax, October 2006

1835 Andy Snell and Jonathan P. Thomas, Labour Contracts, Equal Treatment and WageUnemployment Dynamics, October 2006

1836 Peter Backé and Cezary Wójcik, Catching-up and Credit Booms in Central and Eastern European EU Member States and Acceding Countries: An Interpretation within the New Neoclassical Synthesis Framework, October 2006

1837 Lars P. Feld, Justina A.V. Fischer and Gebhard Kirchgaessner, The Effect of Direct Democracy on Income Redistribution: Evidence for Switzerland, October 2006

1838 Michael Rauscher, Voluntary Emission Reductions, Social Rewards, and Environmental Policy, November 2006

1839 Vincent Vicard, Trade, Conflicts, and Political Integration: the Regional Interplays, November 2006

1840 Erkki Koskela and Mikko Puhakka, Stability and Dynamics in an Overlapping Generations Economy under Flexible Wage Negotiation and Capital Accumulation, November 2006

1841 Thiess Buettner, Michael Overesch, Ulrich Schreiber and Georg Wamser, Taxation and Capital Structure Choice - Evidence from a Panel of German Multinationals, November 2006

1842 Guglielmo Maria Caporale and Alexandros Kontonikas, The Euro and Inflation Uncertainty in the European Monetary Union, November 2006

1843 Jan K. Brueckner and Ann G. Largey, Social Interaction and Urban Sprawl, November 2006

1844 Eytan Sheshinski, Differentiated Annuities in a Pooling Equilibrium, November 2006

1845 Marc Suhrcke and Dieter Urban, Are Cardiovascular Diseases Bad for Economic Growth?, November 2006

1846 Sam Bucovetsky and Andreas Haufler, Preferential Tax Regimes with Asymmetric Countries, November 2006 
1847 Luca Anderlini, Leonardo Felli and Andrew Postlewaite, Should Courts always Enforce what Contracting Parties Write?, November 2006

1848 Katharina Sailer, Searching the eBay Marketplace, November 2006

1849 Paul De Grauwe and Pablo Rovira Kaltwasser, A Behavioral Finance Model of the Exchange Rate with Many Forecasting Rules, November 2006

1850 Doina Maria Radulescu and Michael Stimmelmayr, ACE vs. CBIT: Which is Better for Investment and Welfare?, November 2006

1851 Guglielmo Maria Caporale and Mario Cerrato, Black Market and Official Exchange Rates: Long-Run Equilibrium and Short-Run Dynamics, November 2006

1852 Luca Anderlini, Leonardo Felli and Andrew Postlewaite, Active Courts and Menu Contracts, November 2006

1853 Andreas Haufler, Alexander Klemm and Guttorm Schjelderup, Economic Integration and Redistributive Taxation: A Simple Model with Ambiguous Results, November 2006

1854 S. Brock Blomberg, Thomas DeLeire and Gregory D. Hess, The (After) Life-Cycle Theory of Religious Contributions, November 2006

1855 Albert Solé-Ollé and Pilar Sorribas-Navarro, The Effects of Partisan Alignment on the Allocation of Intergovernmental Transfers. Differences-in-Differences Estimates for Spain, November 2006

1856 Biswa N. Bhattacharyay, Understanding the Latest Wave and Future Shape of Regional Trade and Cooperation Agreements in Asia, November 2006

1857 Matz Dahlberg, Eva Mörk, Jørn Rattsø and Hanna Ågren, Using a Discontinuous Grant to Identify the Effect of Grants on Local Taxes and Spending, November 2006

1858 Ernesto Crivelli and Klaas Staal, Size and Soft Budget Constraints, November 2006

1859 Jens Brøchner, Jesper Jensen, Patrik Svensson and Peter Birch Sørensen, The Dilemmas of Tax Coordination in the Enlarged European Union, November 2006

1860 Marcel Gérard, Reforming the Taxation of Multijurisdictional Enterprises in Europe, “Coopetition” in a Bottom-up Federation, November 2006 